\title{
ENCONTROS DE ORIENTAÇÃO COLETIVA, INTENTOS DE PRODUZIR ESCRITAS A N-1
}

ENCUENTROS DE TUTORIA COLECTIVA, INTENTOS DE PRODUCIR ESCRITURAS A N-1

\author{
Marcela Bautista Nuñez ${ }^{1}$
}

\begin{abstract}
Resumo: As seguintes linhas relatam e problematizam movimentos experimentados no convívio com um grupo de estudantes de Pós-Graduação em Educação e Artes. Os encontros são denominados Encontros de Orientação Coletiva (EOC) e têm por premissa o compartilhamento do conhecimento e problematização de pesquisas num movimento coletivo. Amparados pelas filosofias da diferença com obras de autores como Gilles Deleuze (1992, 1999, 2002, 2009, 2010), Félix Guattari e Gilles Deleuze (1995, 2013, 2017), de modo a produzir possibilidades de linhas de fuga por meio da escrita, estas exigindo um pensar voltado aos processos investigativos da pósgraduação, mestrado e doutorado pela composição, produção e tratamento de imagens, concomitantes a investigações que se realizam permeadas por um grupo que investiga junto e produz junto. Matilha que se articula para produzir escritas a n-1.
\end{abstract}

Palavras-chave: EOC's; escrita; matilha.

Resumen: Las siguientes líneas informan y problematizan los movimientos experimentados al convivir con un grupo de estudiantes de Posgrado en Educación y Artes. Las reuniones se denominan Encuentros de Orientación Colectiva (EOC's) y se basan en el intercambio de conocimientos y cuestionamientos acerca de procesos de investigación en un movimiento colectivo. Apoyados por las filosofías de la diferencia con obras de autores como Gilles Deleuze (1992, 1999, 2002, 2009, 2010), Félix Guattari y Gilles Deleuze (1995, 2013, 2017) de forma a que se desarrollan bocetos de producir líneas de fuga por medio de la escrita, las cuales exigen un pensar sobre los procesos de investigación en posgrados, maestrías y doctorados que se vuelven a experimentar procesos de composición, producción y tratamiento de imágenes concomitantes la investigación dirigida al ámbito de un grupo que investiga y produce escrituras a muchas manos, una jauría articulada a producir escritas a n-1.

Palabras clave: EOC's; escrita; jauría.

\section{Para dar início, tateando um território e suas singularidades...}

A seguinte escrita é acerca de vivências coletivas experimentadas num grupo específico de Pós-Graduação em Educação. Trata-se de uma investigação proveniente de uma pesquisa de mestrado que encontrasse em sua fase de produção de dados. Contudo, o que mobiliza a escrita é problematizar e relatar os processos de produção de pesquisas de mestrado e doutorado em relação a orientações e metodologias orquestradas em seus desenvolvimentos. É um estudo voltado a produção de conhecimento no campo da Educação e Artes, em especial aos processos de produção de imagens e suas relações com a escrita, leitura e pesquisa, onde são esboçados intentos de abolir quaisquer hierarquias entre essas linguagens.

O grupo em questão está integrado a universidade, local este em que se concretiza e se vivencia o rígido modelo vertical de mundo e de organicidade, onde uma ordem gradual das coisas permeiam os ambientes, as relações, os conteúdos de disciplinas curriculares, assim

\footnotetext{
${ }^{1}$ Licenciada em Artes Visuais pela Universidade Federal de Santa Maria/UFSM. Especialista em Gestão Educacional pela UFSM. Mestranda no Programa de Pós-Graduação em Educação (PPGE/UFSM). E-mail: marcelachemy@gmail.com.
} 
como currículos pessoais, onde o fantasma da individualidade nos sussurra acerca de uma tal 'autossuficiência acadêmica' que em hipótese devemos alcançar para 'sermos melhores', nem é preciso dizer que acaba por se tornar a priori um território um tanto hostil para muitos.

Um entorno que acaba por nos capturar nas mais variadas instâncias, porém, esse rígido muro invisível é vulnerável a rachaduras e sulcos, permitindo assim dar passagem a aquilo que ainda não se sabe, forças desconhecidas que nos possibilitam cunhar realidades outras, diferentes das já estabelecidas. São esses 'entres' que nos interessam, é neles que nos debruçamos ao desconhecido, é esse 'meio' o qual o adubamos para ver germinar a vida, uma vida de raízes fasciculadas, com múltiplas conexões. Queremos o múltiplo, queremos rizoma, relações-rizoma, pesquisas-rizoma, escritas-rizoma, alianças-rizoma, contágios-rizoma.

Um rizoma não começa nem conclui, ele se encontra sempre no meio, entre coisas, inter-ser, intermezzo. A árvore é filiação, mas o rizoma é aliança, unicamente aliança. A árvore impõe o verbo "ser", mas o rizoma tem como tecido a conjunção "e... e... e...". Há nesta conjunção força suficiente para sacudir e desenraizar o verbo ser. [...] reverter a ontologia, destruir o fundamento, anular fim e começo. [...] É que o meio não é uma média; ao contrário, é o lugar onde as coisas adquirem velocidade. Entre as coisas não designa uma correlação localizável que vai de uma para outra e reciprocamente, mas uma direção perpendicular, um movimento transversal que as carrega uma e outra, riacho sem início nem fim, que rói suas margens e adquire velocidade no meio (DELEUZE; GUATTARI, p. 48-49, 1995).

Com tais anseios descritos anteriormente nos nutrimos para poder criar, produzir, escrever e pesquisar. Criamos alianças com autores como Gilles Deleuze (1992, 1999, 2002, 2009, 2010), assim como com suas obras desenvolvidas a quatro mãos com Félix Guattari (1995, 2013, 2017). Como dito anteriormente queremos o múltiplo, para isso nas seguintes linhas explanaremos acerca de alguns movimentos realizados no desenvolvimento da investigação aqui tratada, assim como materialidades, produção de problemas e conexões pulsantes de um grupo que estuda junto e escreve para pensar.

\section{Produção de conhecimento nos Encontros de Orientação Coletiva, que bando é esse?}

O grupo o qual foi estudado e acompanhado durante a pesquisa está inserido dentro da linha de pesquisa 4 - Educação e Artes (LP4²), a qual é uma das quatro linhas de pesquisa existentes dentro do Programa de Pós-Graduação em Educação ${ }^{3}$ (PPGE - Universidade Federal de Santa Maria). O grupo realiza os denominados Encontros de Orientação Coletiva (EOC's), onde mestrandos e doutorandos sob orientação da professora Marilda Oliveira de Oliveira ${ }^{4}$ se

\footnotetext{
${ }^{2}$ A LP4 é composta atualmente por quatro professores/as, sendo estes/as: Ana Lúcia Marques e Louro - Hettwer, que desenvolve pesquisas acerca da formação de professores/as especialistas e não especialistas em música, narrativas e aprendizagens no cotidiano e estudos sobre o ensino superior de música; Cláudia Ribeiro Bellochio que desenvolve pesquisas acerca da formação e práticas pedagógicas na Educação Básica e desenvolvimento profissional dos/das professores de música; Marcelo de Andrade Pereira, que desenvolve pesquisas sobre práticas pedagógicas críticoperformativas, educação e estética, performance e educação, arte e política; Marilda Oliveira de Oliveira, que pesquisa docência como campo de experimentação em artes visuais, formação docente e as filosofias da diferença.

${ }^{3}$ As linhas de pesquisa do PPGE são nomeadas do seguinte modo: LP1 - Formação, Saberes e Desenvolvimento Profissional, LP2 - Práticas Escolares e Políticas Públicas, LP3 - Educação Especial e LP4 - Educação e Artes.

${ }^{4}$ Professora Associada do Departamento de Metodologia do Ensino, do Centro de Educação, da Universidade Federal de Santa Maria, onde atua na Graduação nos Cursos de Licenciatura em Artes Visuais. Professora credenciada no
} 
reúnem para conversar acerca do escopo teórico, produção de imagens e desenvolvimento de escritas, leituras e investigações.

Os estudos e leituras conversadas no grupo são permeados pelo escopo teórico das filosofias da diferença, estas divergem das filosofias da representação, do Uno, pois tomam a diferença em si mesma, pensa o outro em si, como singularidade. Pensar a diferença é pensar o próprio pensamento que se dá sempre pela diferença, e não pela semelhança e/ou identidade (representação). Desse modo as artes, as ciências e a filosofia encontram-se nesse espaço da diferença, com suas singularidades e peculiaridades, cabíveis de serem agenciadas e relacionadas.

As filosofias da diferença não buscam julgar ou se afirmar como verdade frente a outros pensamentos filosóficos, e quando se referem a diferença, não fazem menção a uma concepção que a toma como princípio de identificação (representável), e sim como concepção aberta, não excludente, em outras palavras, diferença pura (DELEUZE, 2009). Deste modo, possibilitam um respiro nas estruturas rígidas e majoritárias que nos cercam. Assim, estar à deriva no pesquisar, sem um caminho já traçado e direcionado, por vezes, pode ser algo potente. Ao referirmo-nos a potente/potência, a entendemos como uma força que nos incita a movimentarmo-nos entre o que nos é estabelecido e o que nos compõem, aumentando assim os bons encontros (DELEUZE, 2002), sentidos que potencializam nossos mais variados modos de existir.

Os EOC's têm por objetivo principal a problematização de imagens e escritas produzidas pelos/pelas estudantes em processo de doutorado e/ou mestrado, de maneira a compartilhar dúvidas, questões teóricas e imagéticas. Cada pesquisa em desenvolvimento é acompanhada pelas leituras coletivas dos colegas, à guisa de pensar junto o escopo teórico ao qual o grupo se aproxima. As dinâmicas do grupo são repensadas quando necessário, de maneira que sejam possíveis as leituras coletivas e conversações sobre as pesquisas realizadas.

Os EOC's nem sempre foram nesse formato, diversos métodos foram operados no grupo, e a cada necessidade de mudança a mesma foi feita por meio da participação de todos e todas, para que assim cada integrante se sentisse à vontade de sugerir e propor outros formatos. Houve um período que trabalhamos com pareceres ao modo de uma banca de qualificação. Esse procedimento deixou de ser produtivo quando o grupo cresceu, e o fato de no final da orientação o orientando/a ter 8 ou 9 pareceres para atender, tornou-se mais trabalhoso do que produtivo.

A metodologia que temos operado atualmente nos EOC's tem sido de discussão página a página do trabalho escrito assim como as imagens. A cada página cada um dos membros coloca o que naquela página merece ser comentado ou destacado. Essas relações coletivas têm muito a contribuir com o andejar de cada estudante-docente-pesquisador/a pois, no exercício em que penso com o outro/a e não como o outro/a (DELEUZE, 2010) esboçam-se possibilidades de aprendizado e criação, produzindo sentidos às relações, coisas compartilhadas e conversadas em grupo. Os destaques e comentários são feitos acerca das escritas e imagens com problematizações acerca dos conceitos, noções e autores/as, desse modo conversamos e problematizamos a composição como um todo e as relações produzidas no decorrer das investigações.

Não nos apoiamos na fixidez de passos preestabelecidos. Apostamos no processo da composição e da colagem, que sobrejustapõem elementos diversos, sem eixos e sem origens, sem prescrições rígidas de como e onde usá-los. Compactuamos com a imanência, com o aqui e agora, com os diversos planos sobrepostos e justapostos em ato. Subvertemos procedimentos, propondo uma investigação como artesania. Apostamos no rigor e no cuidado

Programa de Pós-Graduação em Educação, Mestrado e Doutorado (PPGE/ CE/UFSM), na Linha de Pesquisa: Educação e Artes. Coordenadora do GEPAEC - Grupo de Estudos e Pesquisas em Arte, Educação e Cultura da UFSM. 
que não engessem possibilidades e mundos possíveis e incompossíveis. Não reconhecemos a separação entre teoria e prática (MOSSI, 2017, p. 160).

Não acatamos a ideia de uma prática e teoria separadas, ambas fazem parte do mesmo plano assim como uma fita de Moebius ${ }^{5}$, teoria e prática estão em constantes movimentos reverberantes que propagam um fazer artesão, imbricado entre ambas noções. Nesses movimentos, criar torna-se um ato visceral ao estar à espreita na pesquisa, não como uma busca por algo imaginado e/ou utopístico e sim um acolhimento ao que pode ser potente, estar atentos aos encontros que o/a afetaram em meio a suas escritas, escolhas, composições, inquietações e conversações. Nenhum/a solitário/a e sim compostos/as de múltiplas vozes, múltiplos trajetos a serem optados, recortados, rejeitados, rachados... em devir, num devir animal...

Nesses movimentos de partilha nos EOC's, potencializamos os sentidos que atribuímos as coisas e consequentemente vivenciamos os processos de criação de cada colega, estando à espreita como um animal, territorializando seus mundos, produzindo seu mundo sob territórios moventes, tendo que saber lidar com mudanças climáticas, acontecimentos, infortúnios, coisas inesperadas! Gilles Deleuze, em entrevista com Clarie Parnet $(1988)^{6}$, diz que "O escritor está à espreita, o filosofo está à espreita. É evidente que estamos à espreita. $\mathrm{O}$ animal é... observe as orelhas de um animal, ele não faz nada sem estar à espreita, nunca esta tranquilo." Esta fala nos faz pensar em como nos sentimos ao estarmos imersos em mundos-pesquisa, concomitantemente ao tempo em que fazemos breves sobrevoos e/ou passeios nas pesquisas dos colegas, e nesses encontros nos contaminamos, produzimo-nos, somos permeados por falas, leituras, imagens... elas podem tornar-se viscerais à medida que as visitamos e lhes damos sentidos. Uma passagem de Deleuze em conversa com Parnet (1988), possibilita aberturas que movimentam o pensamento ao pensar as leituras realizadas nos EOC's, sendo esta,

GD: Quando se escreve, não se trata de história privada. [...] Escrever não é assunto privado de alguém. É se lançar, realmente, em uma história universal e seja romance ou a filosofia, e o que isso quer dizer...

CP: É escrever 'para e pelo', ou seja, 'para uso de e no lugar de'. [...] O escritor é um bruxo, pois vive o animal como única população frente à qual é responsável.

Quando escrevemos, não falamos de nós, falamos, escrevemos acerca e sobre dos outros que nos habitam, das vozes que nos produziram, dos silêncios que nos produz, assim como das músicas, das pinturas, das publicidades, dos poemas, das conversas das quais não participamos... assim como das que enfáticos falávamos.

Estabelecemos alianças com o que nos perpassa durante os EOC's e 'fora' deles. Damos ênfase aos processos, ao que criamos em meio a eles, escrevemos com as coisas que nos aproximam, coisas que garimpamos das nossas vivências, escrevemos e produzimos imagens tornando sensíveis as intensidades que nos atravessam, estudamos, lemos e criamos para libertar a vida. Somos matilha. "Num devir animal, estamos sempre lidando com uma matilha, um bando, uma população, um povoamento, em suma, com uma multiplicidade" (DELEUZE; GUATTARI, 2017, p. 20).

\footnotetext{
${ }^{5}$ Também conhecida como fita de Mobius, foi criada em 1858 por August Ferdinand Mobius, trata-se de um plano topológico que é adquirido mediante uma fita, a qual tem suas extremidades coladas, porém antes disso é feita uma torção no corpo da fita, de modo a que um dos lados dessa fique contorcido, formando assim um plano duplo, onde por ambos lados se chega a um mesmo ponto ou plano.

${ }^{6}$ No Brasil, foi divulgado pela TV Escola, Ministério da Educação. Tradução e Legendas: Raccord [com modificações]. A série de entrevistas, feita por Claire Parnet, foi filmada nos anos 1988-1989.
} 
Pessoas cada qual com suas singularidades, convivendo afim de libertar a vida e contagiar outras, matilha não da ordem do hereditário, nem da ordem da reprodução de características e/ou comportamentos, e sim povoamentos por contágios, pandemias de vida, movimentos sinérgicos de heterogêneos, voltados à processualidade e ao que nos acontece, ao que nos toca e ao que é possível produzir nesses 'entres'.

É quando logramos rachar as estruturas que residem em nós (dos mais variados aspectos) que abrimos lugares desconhecidos, criamos sulcos de potencias e é neles onde reside a magia da criação, onde assiduamente movimentamos os andejares da pesquisa e criamos nosso estilo.

O estilo em filosofia é o movimento do conceito. Certamente, este não existe fora das frases não tem outro objetivo senão o de dar-lhe vida, uma vida independente. $\mathrm{O}$ estilo é uma variação da língua, uma modulação, e uma tensão de toda linguagem em direção a um fora. Em filosofia é como um romance: deve se perguntar "que vai suceder?", “o que se passou?". Só que os personagens são conceitos, e os meios, as paisagens, são espaços-tempos. Escrever-se sempre para dar a vida, para libertar a vida aí onde ela está aprisionada, para traçar linhas de fuga. Para isto, é preciso que a linguagem não seja um sistema homogêneo, mas um desequilíbrio, sempre heterogêneo: o estilo cava nela diferenças de potências entre as quais alguma coisa pode passar, pode se passar, surgir um clarão que sai da própria linguagem, fazendo-nos ver e pensar o que permanecia na sombra em torno as palavras, entidades que cuja existência mal suspeitávamos (DELEUZE, 1992, p. 180).

Cavamos a linguagem, plantamos potências, criamos conceitos, colhemos existências que nos eram desconhecidas. Nos lançamos nas diferenças sem medos, criando conexões com os mais variados heterogêneos, fazemos existir. Criamos.

Ao estarmos imersos na convivência em matilha, nesses territórios móveis onde produzimos nossas escritas, imagens e investigações, num grupo que investiga e produz juntos, atravessados por múltiplas vozes, realizamos nossas pesquisas estando à espreita do que nos convoca a criar. Os EOC's pensados com o conceito de matilha dissertado por Gilles Deleuze e Félix Guattari, nos possibilita vivenciar a coletividade de modo transversal, rizomático, pois durante a produção das escritas científicas, dissertações e teses, somos contagiados (não convencidos) uns pelos outros, sem herdar traços nem particularidades, pois a todo momento somos surpreendidos por desvios e acontecimentos inesperados nesse território movente que é a investigação.

\section{O que nos atravessa entre educação, arte e filosofia: o que pode a noção de pasearse...}

Foram os EOC's, assim como o que foi e vem sendo produzido neles que inquietou-me a escrever sobre os processos de produção cientifica, assim como dissertar o processo investigativo que me inspirou a produzir esta escrita a qual é proveniente de uma investigação de mestrado que está em andamento. Posso dizer que a materialidade escolhida foram as produções das teses e dissertações em especial os processos os quais me alcançam perante as produções. Não deixando de lado as materialidades que vão sendo produzidas no decorrer da investigação tais como imagens, poemas, diários, composições... Contudo o problema que estabelecido foi o de como escrever acerca desses processos tão singulares e heterogêneos, assim em como produzir relações com estes sem ter de descrevê-los e/ou explica-los passo a passo, ressalto que a intenção não é a de elencar verdades nem modos de se pesquisar.

Para isso conto com as relações que estabeleci com os autores e autoras durante os estudos, e com cujas teorias escrevemos acerca de como nos aventuramos a criar esse plano 
movente conceitual para apresentar a você leitor partes dos processos investigativos realizados nos EOC's num Programa de pós-graduação em Educação.

Ao ter essa atitude investigativa percorri alguns pontos os quais considero pertinentes acerca de como se dão os processos investigativos nesse singular grupo de orientação. Para isso parti da necessidade que o problema de pesquisa esboçava, travava-se de como escrever processos investigativos de outros sem estes serem descritos ou até colocados como método de pesquisa. Considerando que esses são povoamentos amparados pelas relações criadas entre Educação, Artes e Filosofia, modos singulares, que mestrandos e doutorandos produziram para situar o caos em movimento.

Para isso junto a obras de autores e autoras das filosofias da diferença, me servi da ideia da criação de conceitos e aos poucos fui nutrindo o plano móvel da noção/conceito de pasearse $e^{7}$. Este conceito foi pensado concomitantemente ao momento em que o problema investigativo tomou forma, pois a experiência de pesquisa tratada nesta escrita diz respeito ao problema criado para a dissertação. O problema central tratou-se em como transitar em meio as dissertações e teses produzidas num específico grupo do qual também faço parte, como olhar esses escritos sem me contaminar e cegar por um deslumbre e admiração. Muitas vezes questionei em como um conceito vai se constituindo, assim como os movimentos que realiza para lograr "ser" o que ele é? Porém, percebi meu equívoco ao querer explica-lo ou ao querer dar-lhe uma forma e ou significado. Portanto, o que posso dizer acerca do pasearse é que não posso dizer o que ele é, pois desse modo estaria fechando-o em uma concepção, e a intenção não é de validá-lo partindo de uma experiência específica.

Nesse emaranhado caótico a possibilidade de criação do pasearse foi fundamental para a continuidade da investigação, assim como no transitar em meio das materialidades.

Segundo o veredicto nietzschiano, você não conhecerá nada por conceitos se você não os tiver de início criado, isto é, construído numa intuição que lhes é própria: um campo, um plano, um solo, que não se confunde com eles, mas que abriga seus germes e os personagens que os cultivam (DELEUZE; GUATTARI, 2013, p. 13).

Pensar o pasearse na escrita me possibilitou ver-me estrangeira de mim, inquirindo fragmentos os quais surgiram durante capturas e sulcos transitórios que marcaram os paseos, abrindo espaços até então desconhecidos. Ao compor o pasearse concomitantemente estou num movimento de pasearse assim como percebendo paseos outros mediante escritas, falas, conversas. Como um/uma viajante nos paseamos por nós mesmos/as em processos sinérgicos, nos pensamos e percebemos ao estarmos no coletivo, nos contatos e conversas. Tomamos as mais variadas rotas, inventamos os caminhos num pasearse subjetivo e talvez esse andejar nos leve a nós mesmos, em movimentos de autoconstituição (AGAMBEM, 2000), sem previsões, sem hábitos, embarcados no próprio corpo, que é o que temos.

Territórios de morada provisória que potencializaram e fizeram parte de muitos, espaços onde criamos estando em uma solitude povoada, em especial no desafio de sobreviver ao território

\footnotetext{
7 Ao pensar o pasearse, fazemos referência a uma passagem onde Giorgio Agambem (2000) cita a obra Compedium Grammatices Linguae Hebraeae (1925), do filósofo Espinosa, em seus escritos explica que tal terminologia faz menção a um sentido imanente explanando que "[...] uma causa imanente, isto é, de uma ação em que agente e paciente são uma única e mesma pessoa 'constituir a si visitante', 'mostrar a si visitante' [...] movimento infinito de autoconstituição e auto-apresentação do ser: o ser como pasearse (AGAMBEM, 2000, p. 185)". Autoconstituição, autoprodução, potência, produção de problemas/caminhos à transitar em si, pasear, pasearse. Verbo reflexivo que expressa uma ação operada no sujeito, que recebe e faz a ação em questão, agente e paciente. O termo pasearse provém do idioma Ladino (ou judeu-espanhol).
} 
vertical da pós-graduação, nessa singular experiência, onde a criação nos perpassa impulsionandonos a libertar a vida. Pois, "toda criação é singular, e o conceito como criação propriamente filosófica é sempre uma singularidade. (DELEUZE; GUATTARI, 2013, p. 13)”. E toda singularidade é povoada de diversas vozes. Sendo esta pesquisa permeada por imagens e momentos onde a literatura ocupa um lugar no texto, são modos de forjar a escrita e o plano da investigação, para tatear caminhos possíveis para a criação. Desse modo nos sentimos amparadas na utilização de textos evocativos, contextuais e vernáculos nas nossas pesquisas, sendo assim, um texto da escritora Eliane Brum, afetou-me para compor e pensar junto a outras formas de textos o conceito de pasearse. O texto em questão é "Espelho, espelho não meu...". A autora assim escreve,

Não visitamos Roma, Nova York ou Paris, as pirâmides do Egito, o deserto do Saara, as savanas africanas, o Rio de Janeiro, a Amazônia ou o outro lado da rua. O que fazemos é revisitar a nós mesmos no contato com diferentes culturas e percepções de mundo. A mudança de paisagem ilumina os cantos escuros dos precipícios e as profundezas dos lagos que nos habitam. Sempre esperamos que exista em nós um belvedere, é esta a nossa expectativa ao viajar. E nem sempre é um belvedere o que encontramos. Por isso toda viagem é subjetiva e, possivelmente, quando detestamos um lugar ou um povo é porque não gostamos do que vimos em nós (BRUM, 2010, s.p).

Em algumas oportunidades foi possível falar e apresentar o decorrer da investigação, em momentos fomos questionadas de modo a explicar o que é o pasearse, esses momentos foram muito potentes para notar o que as pessoas percebiam acerca da criação de conceitos, noções e de problemas. Entendemos e compreendemos que somos condicionados a esperar respostas, verdades, métodos, modos de fazer, pois somos educados e escolarizados para isso em grande medida.

Esse preconceito é social (pois a sociedade, e a linguagem que dela transmite as palavras de ordem, "dão"-nos problemas totalmente feitos, como que saídos de "cartões administrativos da cidade", e nos obrigam a "resolvê-los", deixando-nos uma delgada margem de liberdade). Mais ainda, o preconceito é infantil e escolar, pois o professor é quem "dá" os problemas, cabendo ao aluno a tarefa de descobrir-lhes a solução. Desse modo, somos mantidos em escravidão. A verdadeira liberdade está em um poder de decisão de constituição dos próprios problemas: esse poder, "semidivino", implica tanto o esvaecimento de falsos problemas quanto o surgimento criador de verdadeiros (DELEUZE, 1999, p. 11).

Segundo Deleuze em seu livro Bergsonismo, a primeira regra da intuição como método filosófico é "denunciar os falsos problemas, reconciliar verdade e criação no nível dos problemas (DELEUZE, p. 08, 1999)", ao considerarmos esse ponto, podemos dizer que o problema pode tornar-se um motor propulsor que nos movimenta em meio a criação, de modo a que vamos movimentando-nos por meio dele, concomitantemente ao tempo em que vamos criando caminhos para dar-lhe sentidos e respostas provisórias, assim como criando outros problemas, materialidades e territórios desconhecidos.

Tomando os problemas como propulsores assumimos nas nossas investigações a potência da criação de problemas, assim como vivenciamos visceralmente as filosofias da diferença, como um exercício de abraçar a multiplicidade, assim como opera-la. É estar aberto as possibilidades e saber que respostas são provisórias, e que só cabe a nós criarmos nossas realidades e trajetos, assim como os modos os quais vamos a estar a pasearnos em tais caminhos. Em tempo, quando fomos produzindo a escrita dando-lhe formas e planos justapostos ao conceito, criando assim um plano 
móvel composto por múltiplos heterogêneos em continua conexão. Com essas escolhas, e estando à espreita logramos movimentarmo-nos em meio as materialidades e esboçando linhas que provisoriamente traçaram sentidos, os quais foram sendo esboçados durante o processo, escrevendo sobre as experiências e sentidos atribuídos ao andejar investigativo, de modo a que vamos afetando os caminhos da pesquisa ao mesmo tempo em que somos afetados por ela, assumindo-nos como paseadores pelos planos móveis da investigação.

\section{Para concluir brevemente... imagens para pensar e escritas a n-1}

Uma característica que atravessa as produções como grupo é o tratamento das imagens nas pesquisas, as quais adquirem um outro valor além do hierárquico e já conhecido -texto sob imagem. Nos servimos de imagens que não se sobrepõem ao texto, produzimos imagens que nos convidam a pensar, imagens que são produzidas no decorrer investigativo, que se compõem junto ao texto. "Imagens não são extremos opostos das palavras, tampouco são suas sinônimas diretas. São entres, blocos de naturezas diversas dessas últimas que podem (ou não) ser com elas friccionadas, flechadas, atravessadas, gerando fluxos incertos" (MOSSI, 2017, p. 187).

Penso que tais fluxos incertos podem ser o que criamos, as relações que estabelecemos quando nos encontramos com imagens não representativas nos textos, imagens que não têm por proposito ilustrar a escrita, nem ilustrar as questões que ela trata. Imagens que valem por uma imagem e que compõem a obra junto ao texto, de modo a incitar o pensamento a produzir encontros e relações possíveis.

Tal exercício não é algo fácil, não há receita. Pensamos e produzimos as imagem como disparadoras para possíveis conexões, das quais não conhecemos a priori o que pode estar por vir, lhes atribuímos sentidos, que talvez a cada leitura e ou encontro, possamos atualizar os mais singulares pensamentos...

Nesse movimento partilhado realizado nos EOC's, potencializamos os sentidos que atribuímos as coisas e consequentemente vivenciamos os processos de pesquisa dos/das colegas que integram o grupo, estabelecendo alianças com o que acontece durante os EOC's, de modo a que são encontros coletivos que potencializam os processos investigativos, produzindo sentidos, afetos e potências no aprender, dando ênfase aos processos investigativos que acontecem em matilha.

Penso que é produtivo dar sentidos ao aprender (verbo) que se dá em encontros coletivos, onde estamos abertos a expor nossos pensamentos, problemas de pesquisa, inquietações e sentidos dados as coisas. Compartilhar o conhecimento, problematiza-lo, torna-o singular caminho investigativo, mais leve e potencializante para o/a pesquisador/a, pois é possível sentir-se mais acolhido frente ao universo de pesquisa que possui em sua concepção aspectos de disputa e segregação, características estas que acabam por constranger a vida frente a toda sua potência.

No plano movente do pesquisar, escrever e criar, parece sempre haver um intervalo entre o que desejamos e o fato, nem sempre escrevemos aquilo que pensamos ou queremos dizer... Escrevemos exaustivamente para de algum modo dobrar a própria linguagem e até o idioma, para extrair-lhes o singular de cada um/uma de nós. Escrevemos composições de sensações para sensibilizar as forças que nos arrebatam durante os processos investigativos da pesquisa e durante a vida. Escrevemos, porém não somos os/as donos/as do que escrevemos. Toda escrita é permeada por forças, intensidades e contágios de outras escritas, de outras imagens de outras conversas. Nos EOC's, criamos pontes com diferentes territórios, produzimos vizinhanças, e apagamos os contornos das fronteiras, mesmo que de modo provisório... E concomitante ao 
tempo em que apenas intentamos realizar esses movimentos, pode-se dizer que já experienciamos um devir-animal que se potencializa em bando.

\section{Referências}

AGAMBEN, Giorgio. A imanência absoluta. In: ALLIEZ, Éric. Gilles Deleuze: uma vida filosófica. São Paulo: Editora 34, 2000. p. 169-192.

BRUM, Eliane. Espelho, espelho não meu. Revista Época. Brasil, 25 out. 2010. Disponível em: http://revistaepoca.globo.com/Revista/Epoca/0,EMI181755-15230,00-

ESPELHO+ESPELHO+NAO+MEU.html. Acesso em: 20 dez. 2019.

DELEUZE, Gilles. O abecedário de Gilles Deleuze. Realização de Pierre-André Boutang, produzido pelas Éditions Montparnasse: Paris, 1988.

DELEUZE, Gilles. Conversações. São Paulo: Editora 34, 1992.

DELEUZE, Gilles. Bergsonismo. Trad. Luiz B. L. Orlandi. Editora 34: Rio de Janeiro, 1999.

DELEUZE, Gilles. Espinosa, filosofia prática. São Paulo: Editora Escuta, 2002.

DELEUZE, Gilles. Diferença e repetição. São Paulo: Editora Graal, 2009.

DELEUZE, Gilles. Proust e os signos. Rio de Janeiro: Forense Universitária, 2010.

DELEUZE, Gilles; GUATTARI, Félix. Mil platôs, vol. 1: capitalismo e esquizofrenia. Rio de Janeiro: Editora 34, 1995.

DELEUZE, Gilles. GUATTARI, Félix. O que é a filosofia? Editora 34: Rio de Janeiro, 2013.

DELEUZE, Gilles; GUATTARI, Félix. Mil platôs, vol. 4: capitalismo e esquizofrenia. Rio de Janeiro: Editora 34, 2017.

MOSSI, Cristian. Um corpo sem órgãos, sobrejustaposições: quem a pesquisa [em educação] pensa que é? Santa Maria: Editora UFSM, 2017. 